espacio abierto 



\title{
Fanatismo y voracidad cultural. Una relectura de los debates sobre el omnivorismo ${ }^{1}$
}

\author{
Federico Álvarez Gandolfí ${ }^{2}$ \\ Consejo Nacional de Investigaciones Científicas y Técnicas \\ (Conicet), Argentina \\ falvarez@sociales.uba.ar \\ Recibido: 4 de febrero de 2017 \\ Aceptado: 6 de julio de 2017 \\ Disponible en línea: 30 de junio de 2018
}

\footnotetext{
1 Artículo de reflexión. Financiamiento beca doctoral del Conicet en el marco del proyecto de investigación acreditado UbaCyT (2014-2017) "Textos populares y prácticas plebeyas. Cultura de masas, género y fanatismos en la Argentina contemporánea”, financiado por la Secretaría de Ciencia y Técnica de la Facultad de Ciencias Sociales de la UBA.

2 Doctorando en Ciencias Sociales, Magister en Comunicación y Cultura, y Licenciado y Profesor en Ciencias de la Comunicación Social; Facultad de Ciencias Sociales, Universidad de Buenos Aires (Argentina). Becario doctoral del Consejo Nacional de Investigaciones Científicas y Técnicas (Conicet), con lugar de trabajo en el Instituto de Investigaciones Gino Germani, Facultad de Ciencias Sociales, Universidad de Buenos Aires (Argentina).
} 


\title{
Fanatismo y voracidad cultural. Una relectura de los debates sobre el omnivorismo
}

\section{Resumen}

La consigna que orientará este trabajo consiste en reflexionar de modo exploratorio sobre las experiencias culturales e identitarias a partir del consumo en la época actual, tomando como caso a los otakus o fans argentinos del manga y del animé. Teniendo en cuenta conceptualizaciones sobre el periodo histórico "posmoderno" y los acelerados procesos de "mercantilización" que atravesarian las sociedades, se planteará un cruce entre las siguientes dimensiones de problematización: cómo se vinculan los patrones de consumo fan con ciertos mecanismos de distinción, y en qué sentidos el fanatismo cobra una importancia para orientar prácticas de socialización y significación. El propósito teórico general reside en articular las discusiones sociológicas entre la corriente bourdiana de la homología y las tendencias al omnivorismo cultural con los planteos realizados desde los estudios sobre fans, contemplando el despliegue de jerarquías intragrupales que constituyen una zona de vacancia en los abordajes existentes sobre los otakus.

Palabras clave: mercantilización; estudios sobre fans; omnivorismo cultural; otakus; manga; animé

\section{Fanaticism and cultural voracity. A re- reading of the debates on omnivorism}

\begin{abstract}
The guiding principle of this work is to reflect in an exploratory manner on cultural and identity experiences based on consumption in the current era, taking as a case the otaku or Argentine fans of manga and anime. We propose a cross between the following problematization dimensions taking into account conceptualizations about the "postmodern" historical period and the accelerated processes of "commodification" that societies would go through: how fan consumption patterns are linked to certain distinction mechanisms, and how fanaticism becomes important to guide practices of socialization and meaning. The general theoretical purpose is to articulate the sociological discussions between the Bourdian current of homology and the tendencies to cultural omnivorism with the concepts obtained from the studies about fans, taking into account the deployment of intragroup hierarchies that constitutes an empty space in the existing approaches on the otaku.
\end{abstract}

Keywords: commodification; studies about fans; cultural omnivorism; otaku; manga; anime

\section{Fanatismo e voracidade cultural. Uma releitura dos debates sobre onivorismo}

\section{Resumo}

A divisa que orienta este trabalho consiste em refletir de modo exploratório sobre as experiências culturais e indenitárias a partir do consumo no momento atual, tirando como caso os otakus ou fãs argentinos do manga e do animé. Levando em conta conceptualizações sobre o período histórico "pós-moderno" e os acelerados processos de "mercantilização" que atravessariam as sociedades, coloca-se um entrecruzamento entre as seguintes dimensões de problematização: como estão vinculados os padrões de consumo fã com certos mecanismos de diferenciação, e em que sentidos o fanatismo cobra uma importância para orientar práticas de socialização e significação. O propósito teórico geral reside em articular as discussões sociológicas entre a corrente bourdiana da homologia e as tendências ao onivorismo cultural com o que é colocado desde os estudos sobre fãs, contemplando o leque de hierarquias intragrupais que constituem uma zona de vacância nas abordagens existentes sobre os otakus.

Palavras-chave: mercantilização; estudos sobre fãs; onivorismo cultural; otakus; manga; animé 


\section{Consideraciones iniciales}

Este artículo presenta una reflexión sobre el fanatismo en Argentina por el manga y el animé -cómics y animaciones japonesas-, cuyos consumidores suelen ser mujeres y varones jóvenes conocidos como otakus, pertenecientes tanto a sectores medios como populares. La clave interpretativa que guía el análisis de este fenómeno consiste en que el consumo de dichos objetos de la cultura de masas producida en Japón puede dar lugar a diversos usos y apropiaciones por parte de sus fans o aficionados, quienes suelen significarlos como referentes identitarios alternativos en relación con los productos mediáticos comerciales y dominantes.

Para desarrollar y sustentar estas ideas, se contemplarán diversos planteamientos sobre el consumo cultural desde los estudios culturales, la sociología, la antropología y la comunicación. Asimismo, se retomará una investigación propia de carácter etnográfico, empírico y cualitativo, basada en un trabajo de campo en los espacios donde los otakus socializan y en la aplicación de técnicas de observación y entrevista. En este sentido, cabe advertir que este texto se centrará en reflexiones conceptuales sostenidas sobre datos construidos a partir del análisis de los procesos de construcción de identidades y las formas de sociabilidad que se despliegan entre dichos fans. Tanto las descripciones de esos procesos y formas como un desarrollo de sus modos de relevamiento pueden consultarse en trabajos anteriores (Álvarez Gandolfi, 2014, 2015, 2016).

Aquí, el objetivo de presentar interpretaciones referidas al caso particular de los fans argentinos del manga y del animé responde a un interés más general, que radica fundamentalmente en problematizar la discusión sobre el omnivorismo cultural en su carácter de crítica -aunque limitada- a la teoría clásica de la distinción planteada por Pierre Bourdieu. ${ }^{3}$ Por lo tanto, se propone articular dicha

A grandes rasgos, los debates sociológicos sobre el omnivorismo giran en torno de una supuesta mayor amplitud actual del abanico de consumos de productos culturales -como la música, la literatura, el arte, el cine y la televisión- entre las clases dominantes, por la cual sus gustos se extenderían desde "lo refinado" a "lo popular" (Fernández Rodríguez y Heikkilä, 2011). Este nuevo panorama, según los defensores de dicha corriente, debilitaría la potencialidad de las ideas bourdianas para explicar la estratificación de las preferencias culturales vinculándolas de modo estrecho con la clase u origen social de pertenencia por la mediación del habitus: conjunto de disposiciones que estructura las elecciones de 
discusión con los debates dentro de los estudios sobre fans (fan studies), campo consolidado en la academia anglosajona desde los noventa y de incipiente constitución en América Latina.

En este sentido, algunas de las preguntas orientadoras sobre los patrones de consumo fan serán: ¿de qué modos se relaciona el omnivorismo con las prácticas usuales de los fans? ¿Cuáles son los significados que tiene la voracidad cultural para los fans? ¿Qué sectores tienen un amplio abanico de preferencias culturales que podrian abarcar desde lo refinado, lo comercial, lo global y lo nuevo hasta lo popular, lo alternativo, lo local y lo antiguo? ¿Quiénes tienen un abanico estrecho? ¿Cómo se vincula la amplitud de gustos con las actitudes que se adoptan hacia los consumos y estilos de vida de otros fans? Estos interrogantes cobran importancia frente a un contexto cada vez mayor de mercantilización social, en el que la figura del fan se erige como modelo de consumidor ideal y se promueve un consumo voraz que, supuestamente, no permitiría el ejercicio de una distancia crítica ni de un juicio estético.

Según los resultados que se pondrán a discusión en este trabajo, pareciera que en el caso de los fanatismos existe una tensión entre 1) aquellos que ostentan consumir numerosos productos culturales, para no ser estigmatizados como obsesivos, y 2) aquellos que se comprometen con el consumo de un mismo tipo de producto cultural, de forma frecuente y apasionada, como otro modo posible de diferenciarse y adquirir estatus. En este punto, a su vez, se hará hincapié en 3) la persistencia de la puesta en juego de jerarquías intragrupales alrededor de un clivaje de clase, contradictoria con la supuesta flexibilización posmoderna de las fronteras simbólicas, las cuales continúan actuando en la construcción de identidades culturales.

E1 interés por subrayar cómo continúan desplegándose dichas jerarquías reside en que, en su mayoría, los estudios sobre fans en general $-\mathrm{y}$ sobre otakus en particular- tienden a ponerlas entre pa-

los agentes en función de los capitales que poseen y definen su posición en la jerarquía social, de modo que las clases altas se diferenciarían de las clases populares por sus prácticas de consumo y gustos legítimos dada su mayor cantidad de capital cultural. 
réntesis para sistematizar las lógicas propias del fanatismo como fenómeno sociocultural, frente a su estigmatización social y mediática.

En efecto, las escasas y dispersas investigaciones realizadas desde la academia latinoamericana en torno del fanatismo por el manga y el animé, que sirven como antecedentes de este trabajo (Balderrama Gastelú y Pérez Hernáiz, 2009; Correia Lourenço, 2009; Perillán, 2009; Cobos, 2010; Uribe Ruiz y Parada Morales, 2010; López Moraga, 2011; Bogarín Quintana, 2012; Del Vigo y Carpenzano, 2014; Ferrari Nunes, 2015) presentan descripciones exploratorias sobre las dinámicas que atraviesan la construcción de la identidad otaku en esta región.

Según suele señalarse en esos estudios, dichos procesos de constitución identitaria se despliegan alrededor de bases comunes de diferenciación exógena: sea a nivel individual a partir del consumo de historietas y animaciones japonesas; sea a nivel colectivo mediante diversas prácticas socioculturales vinculadas con él. Entre estas últimas, puede mencionarse la participación de los otakus en convenciones o eventos, el cosplay y el intercambio de productos, conocimientos o pareceres sobre el manga y el animé con los que se asocian, tanto cara a cara como a través de plataformas digitales.

La comprensión de las propias lógicas y los significados identitarios que tienen esas prácticas de consumo permite tomar distancia de su persistente patologización, dadas las connotaciones negativas con las que cargan en y por fuera de Japón. En consonancia con los estereotipos corrientes mediante los cuales, desde una perspectiva prejuiciosa y estigmatizante, los discursos sociomediáticos ponen en escena a los fans en general (Jenkins, 2009), los otakus en particular suelen ser representados como figuras peligrosas o risibles, "sociópatas" o "inmaduros" (Borda y Álvarez Gandolfi, 2014).

Pero la necesaria toma de distancia respecto de esos estigmas no debe implicar la asunción de una postura populista celebratoria y simplista que rescate solamente aquellos aspectos que el investigador considere como "positivos" de la cultura fan estudiada, sin 
contemplar sus propios horizontes de sentido. Desde esa postura, las prácticas de consumo vinculadas al fanatismo -en la medida en que suponen un compromiso cristalizado en su reiteración y que puede dar lugar a nuevas producciones por parte de los consumidores fans- han sido caracterizadas y analizadas en términos de "productividad", "autonomía", "resistencia" y "alternatividad" en relación con las lógicas comerciales dominantes de las industrias culturales alrededor de las cuales pueden desplegarse.

Una línea interpretativa similar es reconocible en las investigaciones que componen el estado del arte sobre los fans del manga y del animé, citadas anteriormente: ellas se focalizan en sus prácticas y significados compartidos, subrayando los modos en que esos consumos juegan en procesos de unificación colectiva y en la generación de sentimientos de pertenencia. Así suelen hacer referencia a los otakus como un grupo "alternativo", "marginado", "solidario" y "creativo".

Siguiendo con los planteamientos de Borda (2012), a nivel general esta tendencia se condice con los primeros estudios sobre fans: a principios de los años noventa, en los inicios de la constitución del campo, se trataba de positivizar la imagen de la figura del fan sin cuestionar el binarismo descontrolado/emotivo-racional/crítico que la atraviesa. Esto puede responder a la inscripción de las investigaciones en la versión estadounidense de los estudios culturales, cuyos enfoques teóricos parecieran no mostrarse tan interesados en analizar las estructuras de poder o las jerarquías sociales y culturales que atraviesan a todo grupo.

Asimismo, como también señala Borda, la persistencia de las visiones celebratorias en los trabajos sobre fanatismo -y sobre lo que se ha denominado "otakismo" (Álvarez Gandolfi, 2016)- puede explicarse porque los aislados intentos de aplicar el aparato conceptual de Bourdieu en el campo, atentos a tales estructuras y jerarquías, poco pudieron decir de los placeres comunes implicados en los consumos fans de los objetos de la cultura de masas. De este modo, al centrarse en los sentidos de dichos placeres y los procesos identitarios de distinción entre un "nosotros" y un "ellos" -fans y no fans o 
fans de otros referentes-, las citadas investigaciones tienden a dejar en segundo plano los mecanismos intragrupales de diferenciación.

De aquí que el interés de este trabajo consista en dar cuenta de cómo funcionan esas jerarquías entre los fans argentinos del manga y el animé. Para ello se contemplarán tanto los planteos de Bourdieu (1988), referidos a las estrategias de distinción y jerarquización de los estilos de vida según la posesión de capital cultural, como las críticas que se les realizan desde la corriente del "omnivorismo cultural” (Fernández Rodríguez y Heikkilä, 2011), para conceptualizar las formas actuales de diferenciación social a partir del caso de un fanatismo en particular.

Por lo tanto, en primer lugar, en este artículo se explicitarán las bases conceptuales y analíticas que se consideran más apropiadas para analizar el consumo de los mencionados objetos de la cultura de masas japonesa en la Argentina. Luego, se reflexionará en torno de las dinámicas de socialización y construcción de identidades en las que pueden involucrarse los fans de esos productos culturales japoneses, problematizando las caracterizaciones sobre la llamada "posmodernidad" como un periodo de aparente pérdida de referentes identitarios estables en el que el clivaje de clase supuestamente habría quedado desprovisto de su dimensión condicionante. Todo ello apuntará a proponer una relectura de lo que se conoce como las tendencias actuales en la sociología del consumo -el omnivorismo cultural-, a la luz de las discusiones que hacen al campo de los fan studies, teniendo como referencia a las sociedades occidentales cada vez más mercantilizadas.

\section{Consumos culturales y distinciones fan: usos tácticos de la mercantilización}

Según se anticipó, con el propósito más amplio de abordar problemáticas vinculadas con la construcción de identidades culturales, en este trabajo se propone profundizar reflexiones sobre ciertos interrogantes que vienen siendo desanudados desde otra investi- 
gación (Álvarez Gandolfi, 2014). Dichas preguntas se relacionan con los modos posibles de pensar el fanatismo en general, y a los otakus en particular, dentro de un contexto contemporáneo de mercantilización social. Para ello, de entre las opciones analíticas disponibles, y tomando como referencia el eje textos-audiencias, se focaliza en los sujetos consumidores de los productos de las industrias culturales.

Si bien continúan siendo periféricos dentro del campo de la sociología, los abordajes sobre problemáticas asociadas con el consumo cultural pasaron a ser considerados legítimos debido a que, asumiendo un enfoque transdisciplinario, permiten comprender los cambios identitarios y sociales en la época contemporánea (Alabarces, 2012). Asimismo, la decisión de hacer énfasis en qué hacen los sujetos con lo que consumen conlleva el presupuesto de que el consumo de la cultura de masas sirve para algo más que para reproducir la dominación ideológica, función con las que usualmente son asociadas las industrias culturales desde una postura cercana a la teoría crítica desarrollada por los intelectuales de la Escuela de Frankfurt.

Sin embargo, esto no pretende sugerir una supuesta autonomía de los públicos que interpretan y se apropian de los productos culturales de modo activo y creativo, como se inferiria de ciertas tendencias demasiado celebratorias y optimistas dentro de los estudios culturales británicos de la Escuela de Birmingham. Por el contrario, hay que moverse dentro de la contradicción, entendiendo que la cultura de masas puede ser, a la vez, el espacio para una producción de sentidos tanto hegemónicos como subalternos, según el contexto.

Entonces, cabría proponer un desplazamiento articulatorio entre dos concepciones: aquella según la cual, dada la subordinación de la producción cultural a la estandarización que rige toda producción industrial en serie según una racionalidad instrumental funcional a los sectores dominantes, las industrias culturales sirven para "[...] endurecer la inmutabilidad de las relaciones exis- 
tentes" (Horkheimer y Adorno, 1994, p. 193); y el entendimiento de que las audiencias en general, y los fans en particular, no son enteramente manipulados por los medios, sino que participan de procesos de apropiación y negociación de sentidos a partir de los bienes consumidos.

Por otro lado, también deberian considerarse de modo articulado dos enfoques sobre el consumo que, en principio, tienden a ser vistos como opuestos: el decerteausiano y el bourdiano. Según plantea Certeau (2000), cuyas ideas influyeron en las caracterizaciones de Jenkins (2013) sobre los fans como "cazadores furtivos de textos", el consumo se vincula con prácticas cotidianas que implican combinaciones creativas y desvíos tácticos de las lógicas dominantes. Pero, a su vez, según los postulados de Bourdieu, las prácticas de consumo se asocian con estrategias de distinción que permiten a las clases dominantes ubicarse en una posición de superioridad respecto de los sectores populares, reproduciendo así la estratificación del orden social impuesto a partir de las diferencias de gustos y estilos de vida reconocidos como "legítimos" o "vulgares". Así es posible entender que las prácticas de consumo cultural pueden responder tanto a una lógica táctica, correspondiente a la producción, como a una lógica distintiva de reproducción.

La necesidad de las articulaciones señaladas presentaría similitudes con la propuesta de Corcuff (2013), consistente en practicar un relacionalismo metodológico para desplazar los programas más clásicos del holismo y del individualismo. Es decir, poner el foco en las relaciones sociales que tienen lugar en contextos sociohistóricos específicos, "[...] pensar la coproducción de las partes y del todo" (p. 26). No considerar por separado a la sociedad y a los individuos para interpretar los fenómenos sociales, poniendo respectivamente todo el peso en los modos comunes de pensar y accionar que son impuestos por la primera o en las motivaciones que orientan los comportamientos de los segundos. Más bien pensar en términos de condicionamientos circulares entre las instancias individuales y colectivas. 
Un campo posible para poner en práctica esta propuesta metodológica es el campo de estudios sobre fans, consolidado en Estados Unidos y aún incipiente en América Latina, como ya se indicó. Y un abordaje posible para comprender las influencias recíprocas entre los productos de las industrias culturales y sus fans consistiria en problematizar los modos de construcción identitaria y configuración comunitaria en las sociedades contemporáneas mercantilizadas.

A partir de esta última consideración, aquí se propone pensar que una de las funciones de la cultura de masas también reside en proveer materiales sobre cuya base los consumidores pueden experimentar procesos de constitución identitaria y practicar formas comunitarias de socialización. Además, los fans se apropian de los productos de las industrias culturales para realizar nuevas producciones que comparten entre sí y en las que explicitan sus propias lecturas interpretativas: crean textos audiovisuales como los fanvids, textos escritos como los fanfics y textos pictóricos como el fan art, e incluso caracterizan personajes mediante la práctica del cosplay.

Esta idea parte de los planteos de Borda, para quien "[...] hoy en día el fanatismo se ha convertido en un verdadero fondo de recursos -que integra prácticas, actitudes, expectativas y modos de relación y comunicación- disponible para la construcción de identidades colectivas e individuales, tanto duraderas como fugaces [...]" (2012, p. 108).

En el caso particular de los otakus, como ya se señaló, si se acepta partir de este presupuesto, una de las primeras posturas que hay que asumir es la de tomar distancia de las comunes representaciones sociomediáticas que estereotipan y estigmatizan a estos sujetos. Aquí cabe destacar que la patologización y la ridiculización mediante las cuales los fans del manga y del animé -y los fans en general- tienden a ser pensados podrian responder a que, usualmente, también se los ve como sujetos pasivos, alienados y manipulados por el mercado, que consumen todo lo que se les ofre- 
ce sin un criterio estético, al tiempo que no son capaces de asumir una distancia crítica respecto de los objetos de la cultura de masas.

Frente a esa concepción, uno de los caminos posibles para tratar de interpretar los sentidos que adquiere el consumo de manga y animé para sus fans es el abierto por Baudrillard: no concebir el consumo como un modo pasivo de absorción o satisfacción de necesidades, sino más bien como "[...] una actividad de manipulación sistemática de signos" (2007, p. 224), que implica la estructuración de lazos entre individuos a partir de los objetos que consumen y que cobran valor más allá de sus propiedades materiales, en tanto signos culturales que producen significaciones (Baudrillard, 2005). Se trata de lo que Bauman (2007) denomina "consumismo" por el cual la lógica mercantil del consumo abarca todos los ámbitos de la vida.

Así, podría pensarse a los cómics y las animaciones japonesas, o más bien al merchandising asociado a ellas, como objetos-signo que los otakus consumen en su diferencia singular, dentro de las relaciones sistemáticas y abstractas de significación que mantienen con todos los demás objetos-signo, en términos de Baudrillard. Estas mercancias, a su vez, refieren a un entramado de relaciones que dichos fans mantienen entre sí, pues les asignan un valor simbólico por el cual indican sus sentimientos de pertenencia a una misma comunidad o fandom cuyos miembros comparten consumos culturales, lo que les permite distinguirse de otros individuos a través del despliegue de prácticas de significación comunitaria, de producción de sentidos colectivos. En efecto, los fans argentinos del manga y del animé construyen una identidad otaku y configuran una comunidad, sintiéndose parte de lo que denominan un fandom otaku, mediante las prácticas que desarrollan sobre la base del consumo de los objetos de la cultura de masas japonesa.

Ahora bien, ¿por qué el consumo sería un concepto heurístico para entender las experiencias culturales contemporáneas? Y, además, ¿qué lugar ocuparía el fanatismo en ellas? La respuesta que puede esbozarse se vincula con el presupuesto de que, en el contex- 
to posmoderno -coincidente con una etapa de capitalismo tardío o multinacional (Jameson, 1999)-, se asiste a una incredulidad respecto de los metarrelatos (Lyotard, 1987), como se desarrollará en el siguiente apartado.

\section{Consumidores voraces y nuevas estrategias de distinción: significados identitarios del fanatismo en la posmodernidad}

Según diversas caracterizaciones sobre la condición "posmoderna", existiría un descrédito generalizado respecto de los cuadros institucionales que daban unidad organizativa a los significados adjudicables al mundo: familia, escuela, trabajo, sindicatos, Estado-nación, partidos políticos, Iglesia. Estos referentes identitarios tradicionales estarian en crisis al haber perdido su eficacia como aglutinadores de los individuos en un vivir común, en tanto supuestos garantes de una estabilidad simbólica.

Si bien en las sociedades contemporáneas dichos referentes ya no regulan de manera trascendente las prácticas de los individuos como estructuradores de las identidades individuales y colectivas, Dipaola (2010) advierte que esto no debe llevar a dar por sentada una fragmentación social o una tendencia hacia el triunfo del individualismo, con la supuesta pérdida de regulación normativa que estos fenómenos implicarían. De este modo, el autor toma distancia de las concepciones que pueden inferirse de las obras de Beck (2006) y Touraine (2006), relacionadas con un "fin de la sociedad" y el predominio de las "decisiones y elecciones libres" de cada individuo "autoconsciente", "mónada" que se "autorregula" en función de sus necesidades e intereses y a partir de infinitas opciones.

Frente a dichas concepciones, resulta más apropiado analizar las "[...] nuevas experiencias comunitarias e identitarias que ya no se representan en la dimensión orgánica del lazo social, pero tam- 
poco se disuelven en la atomización individualista que acaba obturando la existencia y experiencia de todo vínculo social" (Dipaola, 2010 , p. 161). En este sentido, hay que tratar de comprender el "pacto performativo" (Dipaola, 2013) que da lugar a un nuevo modo inmanente por el que múltiples regulaciones normativas se producen, más que desde un trascendental institucional, en el despliegue constante de las propias prácticas sociales de interacción.

Es en este último sentido que también puede entenderse que cobra relevancia la propuesta de Borda ya destacada: concebir al fanatismo por los objetos de la cultura de masas como un "fondo de recursos" para construir identidades individuales y colectivas. En efecto, aquí se plantea que las prácticas de consumo fan permitirían encontrar sentidos para dar inteligibilidad a las experiencias socioculturales, frente al señalado contexto posmoderno en el que habría una pérdida de significados comunes.

La transformación de la sociedad en un conjunto de incertidumbres y de riesgos, tras la aparente disolución de los vínculos más estables y la "[...] pérdida de seguridades tradicionales en relación al saber hacer, creencias y normas orientativas [...]" (Beck, 2006, p. 164), viene acompañada de una nueva lógica cultural por la cual "convivimos entre imágenes y nos hacemos con las imágenes" (Dipaola, 2011, p. 70) que, en constante circulación, saturan la experiencia social (Featherstone, 2000; Maffesoli, 2005; Baudrillard, 2007; Harvey, 2008).

Por lo tanto, Dipaola (2011) señala que más que rechazar las imágenes como algo "pernicioso", es preciso reflexionar sobre cómo atraviesan la producción de lazos de socialidad en mayor medida que las instituciones tradicionales. Estas imágenes se constituyen en las bases de nuevas formas de articulación colectiva que se producen continuamente tomando como eje el mercado y, en particular, el consumo de los productos de las industrias culturales. En efecto, los cambios económicos implicados por la globalización y, a partir de la década del sesenta, el pasaje de un régimen capitalista fordista de acumulación "rígida" a la expansión de uno de acumulación "flexi- 
ble", acarrean consigo cambios culturales que hacen surgir "[...] formas posmodernas de pensar, sentir y actuar" (Harvey, 2008, p. 315).

Asimismo, se produce una "estetización" de la vida cotidiana y de la experiencia social (Featherstone, 2000), por la cual los objetos de la cultura de masas se convierten en referentes para dar significado a los lazos entre personas y producir estilos de vida. Entonces, al igual que el consumo, los estilos de vida pasan a constituir una práctica de significación, el diseño de un proyecto vital particular y distintivo.

Por otro lado, es precisamente debido a estas transformaciones características de las sociedades de consumo postindustriales, propias del contexto posmoderno contemporáneo, que ha surgido "[...] una necesidad de replantear el análisis del consumidor y de sus formas de distinción simbólica" (Fernández Rodríguez y Heikkilä, 2011, p. 588). En consecuencia, la teoría del omnivorismo sugiere una supuesta superación del sistema de estratificación cultural "rígido", caracterizado por Bourdieu: aparentemente, las clases altas se alejarían de su tradicional esnobismo y exclusividad.

Dicho sistema, según algunos trabajos defensores del omnivorismo (Fernández Rodríguez y Heikkilä, 2011, p. 589), estaría siendo reemplazado por una mayor tolerancia, dado que los consumos culturales de los sectores dominantes se mostrarian más "abiertos" y "respetuosos" hacia la diversidad de gustos y estilos de vida, entregados a cierto hedonismo. Esta apertura se traduciría en la posesión de un amplio abanico de preferencias culturales que los distinguiría de los sectores populares, cuyos miembros -de modo cuestionable- tienden a ser conceptualizados como carentes de interés por las formas simbólicas: mientras que las clases altas serian "omnivoras", las clases bajas son catalogadas como "univoras", en la medida en que se las relaciona con un abanico estrecho de gustos.

En un sentido figurado, los omnivoros tienen la capacidad de disfrutar de objetos de consumo cultural tanto legitimados -aso- 
ciados a su clase- como deslegitimados -asociados a las industrias culturales y a los entretenimientos populares-. Tal eclecticismo, a su vez, suele ser asociado con el supuesto de que, como efecto de la mercantilización y el crecimiento de las industrias culturales, se habrian difuminado los límites entre lo que puede considerarse "alta cultura", "cultura de masas" y "cultura popular", por lo que ese tipo de jerarquías ya no estaría en funcionamiento.

Así, a partir del consumo de objetos de la cultura de masas pueden reponerse expectativas comunitarias y realizarse exploraciones identitarias en la medida en que, tras el descrédito hacia las instituciones tradicionales, los productos de las industrias culturales permiten dotar de significados al mundo y a la vida. Sin embargo, aquí cabe un reparo. Las nuevas experiencias comunitarias e identitarias en las sociedades contemporáneas, posmodernas, suelen ser caracterizadas como "dinámicas" y "flexibles" (Dipaola, 2010). Podria aceptarse esta categorización si se considera que en las propias prácticas de los sujetos se producen múltiples experiencias comunitarias en el encuentro continuo con otras singularidades, donde cada individuo reajusta constantemente su participación para reasegurar los lazos sociales de pertenencia.

También podría coincidirse en que, dado el debilitamiento de la rigidez con la que se estructuraba la experiencia social, aparece un permanente desplazamiento desde una comunidad hacia otra en el flujo indeterminado de sentidos en que cada individuo se inserta, pudiendo rearticular su identidad en cada instancia comunitaria. En efecto, las identidades serian flexibles, pues siempre están en tránsito entre varias referencias simbólicas, y dinámicas, pues siempre están produciéndose en devenir sobre la múltiple experiencia comunitaria.

Pero el hecho de que pueda entenderse a las relaciones comunitarias e identitarias contemporáneas como dinámicas y flexibles no necesariamente implica que ya no se establezcan grupos de pertenencia duraderos y estables. El reconocimiento de esta circunstancia implicaría tomar distancia de las posturas sostenidas por autores como Bauman (2010) y Maffesoli (2005), quienes utilizan 
las siguientes nociones para caracterizar la socialidad y las identidades contemporáneas: flexibilidad, fluidez, fragmentación, liquidez, apertura, fragilidad, volatilidad, fugacidad.

Según planteos asociados con esas posturas, en las sociedades actuales se daría lugar a la aceleración de las innovaciones de productos para explorar nuevos nichos de mercado e inducir necesidades "efimeras" a satisfacer mediante el consumo, en contraste con los mandatos "rígidos" de las instituciones tradicionales. Por lo tanto, en la posmodernidad no habría lugar para compromisos ni proyecciones a futuro, sino solamente para hedonismos y "presentes perpetuos" (Jameson, 1999, pp. 37-38) que se limitarian a reproducir las lógicas del capitalismo consumista, atravesadas por una "obsolescencia programada" que hace que todo sea reemplazable.

No obstante, por el contrario, aquí se plantea que en el panorama sociocultural actual no siempre se construyen identidades que sean "volátiles", es decir, producidas en el marco de relaciones grupales articuladas mediante lazos de socialidad fugaces. Y los trabajos empíricos sobre el fanatismo en general, y sobre los otakus en particular, podrían proveer un ejemplo de ello. En especial si se considera que, a partir del consumo de los productos de las industrias culturales, los fans practican lazos de socialidad entre sí que experimentan como estables, conformando un grupo de pertenencia que no tiene como referencia a las instituciones tradicionales, sino a los objetos de la cultura de masas.

Frente a la inestabilidad simbólica posmoderna, los fans parecieran buscar nuevas fijaciones de sentido. Si bien se verifica un nomadismo, en la medida en que los sujetos se desplazan constantemente entre distintas experiencias comunitarias, también pueden advertirse intentos de restablecer cierta estabilidad. De aquí la importancia que adquiere para ellos la organización y asistencia a eventos mensuales donde se reúnen, o el sostenimiento de interacciones cotidianas mediante plataformas digitales como Facebook y YouTube. 
A través de las prácticas, consumos, estilos de vida y sentimientos compartidos por los otakus se conforman instancias comunitarias de relación con pares, sobre las cuales tratan de sostener identidades autopercibidas como duraderas, que articulan y ponen en circulación en otros ámbitos -como el familiar, el escolar y el laboral-, más allá del propio fandom del que se sienten parte. Así, por ejemplo, estos fans afirman que nunca van a dejar de ser otakus. También consideran que el manga y el animé tienen mayor calidad artística, mejores argumentos e historias complejas que les permiten reflexionar sobre su vida, a diferencia de los productos de las industrias culturales argentinas y estadounidenses destinados a un público infanto-juvenil. Por ello, principalmente, muestran un rechazo hacia las producciones de Cris Morena, Polka y Disney, al igual que para con los contenidos que se emiten actualmente en canales que en un principio transmitian más animé, como Cartoon Network.

De este modo, se autorreivindican como "anormales", "raros" o "diferentes" porque, en comparación con dichos productos culturales dominantes, sostienen que, a pesar de tratarse de "dibujos", el manga y el animé son menos "infantiles", "inocentes" y "previsibles": tratan sobre dramas asociados con la muerte, la violencia, la sexualidad, el existencialismo, la amistad, la autosuperación, la naturaleza, la fe. Ese tipo de apreciaciones indican la puesta en juego de diferentes criterios que operan en las elecciones y preferencias culturales, en contradicción con la supuesta pérdida de capacidad crítica que implicarían los consumos de los fanáticos.

En definitiva, daría la impresión de que al consumir productos de las industrias culturales de Japón estos fans se proponen rechazar las tendencias homogeneizadoras de su contexto sociocultural occidental, dominado por series estadounidenses y argentinas. Y ello dentro del actual panorama posmoderno de sociedades mercantilizadas y multinacionales, en las que las plataformas digitales e Internet adquieren un papel fundamental para el desarrollo de la vida cotidiana. Así parecerían adoptar una actitud cosmopolita asociada con el nuevo modelo de consumidor 
cultural omnivoro, abiertos al consumo de bienes que ponen en escena simbolismos y valores de una cultura otra: la oriental en general, y la japonesa en particular.

Dicha adopción permitiría ilustrar la lógica táctica de las prácticas de consumo fan, a la que se hizo referencia en el subtítulo anterior, en la medida en que da cuenta de los modos en que los fanáticos pueden apropiarse de los objetos de la cultura de masas resignificándolos en función de sus propios intereses y sentidos. En el caso de los otakus, se trata del uso del manga y del animé como referentes alternativos para construir identidades personales y colectivas estables, desviando la lógica de la obsolescencia programada, característica de la mercantilización.

Sin embargo, a su vez, este tipo de caracterizaciones de los otakus no debe perder de vista la lógica distintiva que atraviesa los vínculos entre estos fans, poniendo énfasis en las bases comunes que sostendrian el fandom: el compartir con otros pares consumos y prácticas socioculturales que definirian un estilo de vida distintivo a partir de ellos. Más allá de estos elementos compartidos, los otakus en Argentina no necesariamente sienten empatía con todo aquel que tenga gustos similares, quizás porque al "normalizarse" el consumo de estos objetos de la cultura de masas japonesas perdería su carácter "alternativo", su valor de diferenciación intergrupal. Así como tampoco muestran una mayor "tolerancia" y "respeto" por otros gustos y estilos de vida.

En efecto, los fans del manga y del animé pertenecientes a los sectores medios tratan de diferenciarse de los otakus de sectores populares. De este modo, se constituyen como fans "omnivoros", en el sentido de que tienden a subrayar que, a diferencia de los otakus de sectores populares -que suelen denominar "boliotakus" o "wachiotakus"-, sus consumos no se limitan solamente a dichos productos culturales japoneses, sino que también consumen otros objetos de la cultura de masas. Así tratan de ostentar la posesión de un amplio abanico de gustos $\mathrm{y}$, por este motivo, incluso también llegan a rechazar el calificativo identitario de "otakus", pues lo aso- 
cian con cierta "obsesión" y connotaciones negativas (Ito, Okabe y Tsuji, 2012) ya señaladas.

Pero, al contrario de lo planteado por las nuevas corrientes del omnivorismo cultural (Peterson, 2005, citado en Fernández Rodríguez y Heikkilä, 2011), también es posible advertir entre los otakus de sectores populares un compromiso activo con el consumo de manga y de animé, el cual sería privativo de los sectores dominantes. Si bien estos fans tienden a presentarse como "univoros", en el sentido de que tendrian un abanico estrecho de preferencias culturales basadas exclusivamente en los cómics y las animaciones japonesas, su pertenencia a las clases populares no los inhabilita a involucrarse con prácticas de "consumo voraz" -frecuente y apasionado, aunque exclusivo, a diferencia de la voracidad diversificada que caracterizaria a las clases dominantes-, de dichos productos.

Además, el fanatismo unívoro y, a la vez, voraz de los otakus de sectores populares no se vería restringido a formas culturales "populares" consideradas "vulgares" o de "mal gusto", pues el manga y el animé suelen poner en escena formas culturales elitistas e intelectuales propias de la "alta cultura" -como la música clásica y otras expresiones artísticas literarias o plásticas, según destacan los propios fans-, tradicionalmente creadoras de distinción social, siguiendo la teoría bourdiana.

Hechas estas observaciones, pueden problematizarse los planteos según los cuales las jerarquías culturales han pasado a ser más fluidas, en coincidencia con un periodo histórico posmoderno aparentemente caracterizado por la liquidez y el respeto a la diversidad. Para ello, resulta ilustrador extrapolar los reparos de Alabarces (2015) respecto de los procesos de "plebeyización" de la cultura que tuvieron lugar en la Argentina durante la década de los noventa, por el cual miembros de las clases medias y altas expropiaron prácticas y objetos de consumo vinculados con las clases populares -como la cumbia o el fútbol-, simulando un cuadro de igualdad cultural en un contexto de profundización de las desigualdades materiales. 
Las fronteras simbólicas continúan operando en la construcción de las identidades culturales en general, tanto como en aquellos procesos identitarios que se despliegan en torno del fanatismo en particular. Y la clase u origen social de pertenencia sigue siendo un clivaje que funciona como indicador de una jerarquía. En efecto, según se advirtió, en el caso de los fans argentinos del manga y del animé pertenecientes a los sectores medios se manifestaría un omnivorismo posmoderno que no se traduce en una esperada mayor tolerancia. Por el contrario, estos sujetos ostentarian un amplio abanico de consumos culturales para diferenciarse de los otakus de sectores populares, a quienes tratan de expulsar de su grupo o fandom por asociarlos con otras prácticas de consumo vinculadas por ejemplo con la cumbia, reafirmando su menor valor simbólico en la jerarquía cultural.

Es por ello que resulta fundamental tomar distancia de las posturas que, bajo un aparente respeto "posmoderno" por la diversidad, celebran las dispersiones y fragmentaciones que se expresarian en la lógica cultural del capitalismo tardío, desplazando las preguntas por las relaciones de poder y las formas actuales que cobra la jerarquización en el orden sociocultural. Como trató de plantearse aquí, tanto el fanatismo por el manga y el animé como el consumo voraz con el que puede asociarse -en el sentido de un consumo regular y que implica un involucramiento a nivel emocional, individual y colectivo- son fenómenos que permiten ilustrar la persistencia de estas dinámicas, dentro del contexto contemporáneo de mercantilización y pérdida de estabilidad simbólica.

\section{Consideraciones finales}

Como últimas reflexiones, que den lugar a más investigaciones empíricas y a nuevas problematizaciones, cabe reseñar algunas tareas pendientes: profundizar, desde la puesta en práctica de un relacionalismo metodológico y tomando como caso a los otakus, el análisis de los condicionamientos circulares entre las instancias individuales y colectivas; los vínculos entre las industrias culturales y los patrones 
de consumo fan. Asimismo, ahondar en los modos en que productos mercantilizados y diseñados como objetos obsolescentes para ser consumidos y desechados pueden ser resignificados como base del despliegue de experiencias identitarias e instancias comunitarias estables y duraderas, estructuradas en torno de prácticas fan de consumo cultural; las formas en que las experiencias subjetivas que atraviesan esas reapropiaciones están condicionadas por distintos clivajes como la edad, el sexo, el género y la clase social.

En este artículo se trató de sentar algunas bases que puedan servir como ejes orientadores de ese tipo de futuros abordajes. Con ese objetivo, se consideraron los diferentes sentidos y las múltiples exploraciones identitarias que son posibles a partir de las prácticas de consumo con las que se involucran los fans del manga y del animé en la Argentina. Así se advirtió que, más allá de sus elementos en común -sobre los cuales se sostiene su grupo o fandom y que tienden a ser más conceptualizados tanto en el campo de los fan studies como en el de los estudios sobre otakus-, pueden reconocerse jerarquías internas en función de un clivaje de clase: según el sector social de pertenencia, hay una tendencia a la autodenominación como "otaku" vinculada con un estilo de vida que se define a partir del fanatismo o consumo voraz -aunque exclusivo- de todo aquello asociado con los cómics y las animaciones japonesas.

De este modo, mientras que los fans del manga y del animé pertenecientes a los sectores medios se involucrarian con prácticas de consumo cultural omnivoro para diferenciarse intragrupalmente, los otakus de sectores populares se mostrarian más proclives a cierto univorismo, a estrechar de modo consciente su abanico de preferencias culturales para reivindicarse como alternativos respecto de los productos culturales estadounidenses y argentinos dominantes.

Por lo tanto, es posible pensar que, en realidad, el omnivorismo cultural, en tanto que amplitud "tolerante" del abanico de gustos por diversos productos, funcionaría paradójicamente como una nueva forma de distinción en el sentido bourdiano del término, reforzando las barreras simbólicas entre los omnivoros de sectores 
medios y los miembros de las clases populares que, en este caso, forman parte del mismo grupo de fans. Pero, a su vez, también podría entenderse que la voracidad cultural, por la cual los otakus de sectores populares tienden a sostener que consumen exclusivamente manga y animé, cobra un sentido de diferenciación intergrupal.

En definitiva, se trata de recordar siempre que "[...] no cabe duda de que en la relación de los individuos con la cultura todavía perviven importantes jerarquías, resultado de la organización desigual de las posiciones sociales" (Fernández Rodríguez y Heikkilä, 2011, p. 602).

\section{Referencias}

Alabarces, P. (2012, diciembre). La cultura y la periferia: andanzas nómades de la sociología de la cultura argentina. VII Jornadas de Sociología de la UNLP. Recuperado de http://www.memoria.fahce.unlp.edu.ar/trab_eventos/ev.1663/ ev.1663.pdf

Alabarces, P. (2015). Textos populares y prácticas plebeyas: "aguante", cumbia y política en la cultura popular argentina contemporánea. Alter/nativas, (4), 1-28.

Álvarez Gandolfi, F. (2014). Subcultura otaku. Representaciones, prácticas e identidades juveniles de los fans del manga y el anime en Argentina (Tesis de Licenciatura en Ciencias de la Comunicación). Facultad de Ciencias Sociales, Universidad de Buenos Aires, Argentina.

Álvarez Gandolfi, F. (2015). Culturas fan y cultura masiva. Prácticas e identidades juveniles de otakus y gamers. La Trama de la Comunicación, 19, 45-65. Recuperado de http://www.latrama.fcpolit.unr.edu.ar/index.php/ trama/article/view/514/396

Álvarez Gandolfi, F. (2016). Cibercultura Otaku. Un análisis interdiscursivo de identidades fan puestas en escena en grupos de Facebook. Perspectivas de la Comunicación, 9(2), 31-57. Recuperado de http:/ / publicacionescienciassociales. ufro.cl/index.php/perspectivas/article/view/619/597 
Balderrama Gastelú, L. y Pérez Hernáiz, C. C. (2009). La elaboración del ser otaku desde sus prácticas culturales, la interacción con el otro y su entorno (Tesis de Licenciatura en Sociología). Universidad Católica Andrés Bello, Caracas, Venezuela.

Baudrillard, J. (2005). Crítica de la economía política del signo. México D. F.: Siglo XXI.

Baudrillard, J. (2007). El sistema de los objetos. México D. F.: Siglo XXI.

Bauman, Z. (2007). Vida de consumo. Madrid: FCE.

Bauman, Z. (2010). Mundo consumo. Barcelona: Paidós.

Beck, U. (2006). La sociedad del riesgo. Barcelona: Paidós.

Bogarín Quintana, M. J. (2012). Otakus bajo el sol. La construcción sociocultural del fanático de manga y anime en Mexicali. México: UABC.

Borda, L. (2012). Bettymaníacos, luzmarianas y mompirris: El fanatismo en los foros de telenovelas latinoamericanas (Tesis de Doctorado en Ciencias Sociales). Universidad de Buenos Aires, Argentina.

Borda, L. y Álvarez Gandolfi, F. (2014). El silencio de los otakus. Estereotipos mediáticos y contra-estrategias de representación. Papeles de Trabajo, 8(14), 50-76.

Bourdieu, P. (1988). La distinción. Madrid: Taurus.

Certeau, M. de (2000). La invención de lo cotidiano. México D. F.: UI.

Cobos, T. L. (2010). Animación japonesa y globalización. La latinización y la subcultura otaku en América Latina. Razón y Palabra, 72, 1-28.

Corcuff, P. (2013). Las nuevas sociologías. Buenos Aires: Siglo XXI. 
Correia Lourenço, A. L. (2009). Otakus (Tesis de Doctorado en Antropología Social, Museu Social). Universidade Federal do Rio de Janeiro, Brasil.

Del Vigo, G. A. y Carpenzano, N. A. (2014). Más allá del mundo feliz del fin de semana. Cosplay en la Argentina (Tesis de Licenciatura en Ciencias de la Comunicación). Facultad de Ciencias Sociales, Universidad de Buenos Aires, Argentina.

Dipaola, E. (2010). Socialidades contemporáneas: dinámica y flexibilidad en relaciones comunitarias e identitarias. Nómadas. Revista Crítica de Ciencias sociales y jurídicas, 26(2), 159-185.

Dipaola, E. (2011). La producción imaginal de lo social: imágenes y estetización en las sociedades contemporáneas. Cuadernos Zygmunt Bauman, 1(1), 68-84.

Dipaola, E. (2013). Comunidad impropia. Buenos Aires: Letra Viva.

Featherstone, M. (2000). Estilos de vida y cultura de consumo. En Cultura de consumo y posmodernismo (pp. 142-159). Buenos Aires: Amorrortu.

Fernández Rodríguez, C. J. y Heikkilä, R. (2011). El debate sobre el omnivorismo cultural. Una aproximación a nuevas tendencias en sociología del consumo. Revista Internacional de Sociología, 69(3), 585-606.

Ferrari Nunes, M. R. (Org.) (2015). Cena cosplay. Porto Alegre: Sulina.

Harvey, D. (2008). La condición de la posmodernidad. Buenos Aires: Amorrortu.

Horkheimer, M. y Adorno, T. (1994). La industria cultural. Ilustración como engaño de masas. En Dialéctica de la Ilustración (pp. 165-212). Madrid: Trotta.

Ito, M., Okabe, D. y Tsuji, I. (2012). Otaku Culture in a Connected World. London: YUP.

Jameson, F. (1999). El giro cultural. Buenos Aires: Manantial.

Jenkins, H. (2009). Fans, blogueros y videojuegos. Barcelona: Paidós. 
Jenkins, H. (2013). Textual Poachers: Television Fans and Participatory Culture. Updated Twentieth Anniversary Edition. New York: Routledge.

López Moraga, M. J. (2011). Los fans de la animación japonesa en el gran Santiago (Tesis de Licenciatura en Sociologia). UAHC, Santiago de Chile, Chile.

Lyotard, J.-F. (1987). La condición postmoderna. Madrid: Cátedra.

Maffesoli, M. (2005). El instante eterno. Buenos Aires: Paidós.

Perillán, L. (2009). Otakus en Chile (Tesis de Licenciatura en Antropología). Universidad de Chile, Santiago de Chile, Chile.

Touraine, A. (2006). Un nuevo paradigma para comprender el mundo de hoy. Buenos Aires: Paidós.

Uribe Ruiz, S. y Parada Morales, D. A. (2010). Representaciones sociales en relación al fenómeno manga-anime en jóvenes bogotanos que manifiestan haber construido una identidad como otaku (Tesis de Licenciatura en Psicologia). Fundación Universitaria Los Libertadores, Colombia.

\section{Cómo citar este artículo}

Álvarez Gandolfi, F. (2018). Fanatismo y voracidad cultural. Una relectura de los debates sobre el omnivorismo. Universitas Humanística, 85, 321-345. https:/ / doi.org/10.11144/Javeriana.uh85.fver 